\title{
ESCUTAR INTERPRETAÇÕES E INTERPRETAR: MEMÓRIAS DO "POVO DA AYAHUASCA"
}

\author{
Gerson Rodrigues de Albuquerque ${ }^{1}$
}

\begin{abstract}
A escrita é uma coisa, e o saber outra. A escrita é a fotografia do saber, mas não o saber em si. O saber é uma luz que existe no homem. É a herança de tudo aquilo que nossos ancestrais puderam conhecer e que se encontra latente em tudo o que nos transmitiram, assim como o baobá já existe em potencial em sua semente.

(HAMPÂTÉ BÂ)
\end{abstract}

O objetivo deste ensaio é abordar algumas dimensões das significativas experiências em um curso para jovens e adultos, atentando para a dinâmica do processo ensino-aprendizagem como uma via de mão dupla na qual a produção do conhecimento se processa como parte das diferentes trajetórias dos sujeitos envolvidos. ${ }^{2} \mathrm{O}$ curso foi realizado no âmbito do campus da Universidade Federal do Acre (UFAC), no período de outubro de 2009 e abril de 2010, com a participação de alunos de diferentes idades e localidades, com a finalidade de desenvolver estudos em torno das diferentes formas de abordagem da "história oral", com o objetivo de preparar "agentes culturais" das comunidades ayahuasqueiras. Ao término das atividades teóricas e práticas, os alunos se distribuíram em grupos de diferentes comunidades e desenvolveram todo o processo de pesquisa e redação de Trabalhos de Conclusão de Curso (TCC) a partir dos quais desenvolvemos a presente reflexão.

O interessante da história oral não é escutar uma pessoa te dizer o que aconteceu como se estivesse lendo uma história e várias pessoas te contar do mesmo jeito. $\mathrm{O}$ interessante é escutar interpretações de pessoas diferentes que viveram e viram sob vários ângulos, de vários lados e que te falam cada detalhe minúsculo. Ao mesmo tempo, se você comparar depois, no final, pra você não será a mesma história. ${ }^{3}$

\footnotetext{
${ }^{1}$ Doutor em História Social (PUC-SP, 2001) e Professor da Universidade Federal do Acre, Centro de Educação, Letras e Artes.

${ }^{2}$ Texto publicado originalmente pela Revista Eletrônica "Comunidades Tradicionais da Ayahuasca - construindo políticas públicas para o Acre - Seminário", no ano de 2010. Disponível em: https://goo.gl/xPXYbH.

${ }^{3}$ Reflexões de Antonio Gomes da Silva Neto, 15 anos, em Trabalho de Conclusão do Curso "Formação de Agentes Culturais nas Comunidades Ayahuasqueiras", Rio Branco, Acre, abril de 2010.
} 
Com essas palavras, o mais jovem dos alunos do curso sobre "história oral"4 inicia seu relatório de avaliação das atividades desenvolvidas. O interessante é escutar interpretações de pessoas diferentes. Interpretar é esclarecer e é, também, explicar, traduzir, atribuir sentido às coisas vistas, ouvidas ou vividas, como nos informam ou conformam os dicionários.

Atribuir significados é papel de quem se faz presente e presentifica, atualiza e atribui significados à experiência vivida ou, como nos ensina o jovem Antonio Gomes, escuta a interpretação do vivido e, também, interpreta, porque parte de sua própria experiência. A subjetividade é "uma característica indestrutível dos seres humanos" (PORTELLI, 1996, p. 61), e é, no amplo espectro de suas possibilidades que trilham as memórias de mulheres e homens de "comunidades ayahuasqueiras acreanas", em importante processo de "lembrar", produzir "lembranças" e organizar/inserir essas "lembranças”, em suas casas de memória.

Atividade política de primeira grandeza, a organização dessas casas de memória e a inserção do "documento oral" em seus acervos resulta em revigoramento do debate sobre a importância da memória, da subjetividade e da inter-subjetividade como elemento articulador da própria formulação/elaboração do "documento oral" e de tudo o que vem com o ato de lembrar. Ato que independe da vontade ou da decisão do sujeito - aquele que lembra - a lembrança acomete, no dizer de Beatriz Sarlo, até mesmo quando não é convocada, e em seu tempo próprio: o presente (SARLO, 2007, p. 10).

A memória oral, escreve Ecléa Bosi, longe da unilateralidade para a qual tendem certas instituições, faz intervir pontos de vista contraditórios, pelo menos distintos entre eles, e aí se encontra a sua maior riqueza (BOSI, 2003, p. 15). Partindo dessa perspectiva, podemos depreender a importância do "documento oral" para as casas de memória, especialmente, quando a própria comunidade decide gravar ou registrar, transcrever, catalogar, organizar e possibilitar o acesso aos relatos orais. Trabalho silencioso que exige muita atenção e tempo dos "historiógrafos" e entrevistadores, mas que coloca possibilidades ao discurso homogêneo e ao predomínio da narrativa coletiva "explicadora e legitimadora" de tudo que esteja a serviço do controle e de um determinado poder que procura "transmitir e difundir como referencial de todas as experiências" (BOSI, 2003, pp. 17-18).

O que se busca - no ato de parar e ouvir o outro - é romper as amarras que silenciam o indivíduo no coletivo; que tornam sua trajetória individual um lugar comum da trajetória de

\footnotetext{
${ }^{4}$ Curso de formação de agentes culturais nas comunidades ayahuasqueiras. Câmara Temática de Culturas Ayahuasqueiras do Conselho Municipal de Políticas Culturais de Rio Branco. Fundação Garibaldi Brasil, Lei de Incentivo à Cultura, 2009.
} 
todos. Retomo a perspicaz compreensão de Antonio Gomes que nos desafia a "escutar interpretações de pessoas diferentes" para, no final, percebermos que o resultado de "cada detalhe minúsculo" se constitui como central na formulação de algo que, segundo ele, "não será a mesma história". Em minha opinião, esses "detalhes minúsculos”, os quais diferenciam as narrativas individuais da narrativa coletiva - no caso, aquela que funda a doutrina - são construções mentais resultado da intervenção material e simbólica das mulheres e homens entrevistados que, produzindo leituras sobre o que experienciaram, os projetam e consolidam como seguidores e construtores da doutrina, propagadores de seus efeitos sobre o indivíduo e sobre o coletivo; de suas condutas éticas, morais, sociais.

O sujeito da experiência - individual e coletiva - pensa, interpreta, traduz essa experiência de múltiplas formas. Aquele "que pensa, que espera, que se dedica, pertence à galeria dos iluminados”. Iluminação que, também, é profana, como ressaltou Walter Benjamin (1993, p. 33) e que nos inspira a ouvir/ler as incursões dos agentes culturais de "comunidades ayahuasqueiras", em produção de relatos que tendem a um desordenamento discursivo - a inserção de narrativas orais em suas casas de memória - para preservar suas "tradições", seus saberes, seus ensinamentos, ou seja, para, no tenso campo de disputas que articula e institui toda forma de memória, manter o consenso pelo dissenso.

Tal paradoxo não pode nos eximir de insistir que as lembranças de mulheres e homens pertencentes às comunidades religiosas que fazem uso do chá ayahuasca ou hoaska, com toda sua carga de subjetividades - a exemplo de qualquer documento/testemunho histórico - não é a história "tal qual", a "verdade dos fatos" assim "como ocorreram", mas a leitura possível de um passado que mulheres e homens fazem, num tempo presente, marcado pelas condições objetivas e subjetivas desse tempo. Eis que retornamos às questões formuladas por Sarlo e Benjamin, posto que a "narração inscreve a experiência numa temporalidade que não é a de seu acontecer (ameaçado desde seu próprio começo pela passagem do tempo e pelo irrepetível), mas a de sua lembrança. A narração também funda uma temporalidade, que a cada variante torna a se atualizar" (SARLO, 2007, p. 25).

Não obstante, pensamos que a questão que devemos formular é: qual o significado de inserir a oralidade ou o "documento oral" em casas de memória de comunidades que, historicamente, se organizaram com base em práticas de transmissão oral dos seus conhecimentos e saberes? Esse tipo de iniciativa parece um tanto contraditória, porém, não podemos nos surpreender que isso ocorra, especialmente, porque vivemos num mundo 
marcado pelo predomínio da linguagem escrita e de suas formas de organização/instituição do poder. Poder hierarquicamente estruturado e estruturante a partir da palavra escrita.

A primeira organização cultural/social/espiritual do daime se articula em torno da palavra falada, cantada. Raimundo Irineu Serra, o mestre fundador da doutrina era um homem da oralidade, da escola oralidade em suas múltiplas dimensões. Negro maranhense, filho das diásporas africanas, praticante de uma "nova abordagem da dimensão espiritual das humanidades", para apegar-me às reflexões de Édouard Glissant, recompondo paisagens mentais capazes de articular os processos das muitas misturas que têm marcado as "modernidades" americanas, latinoamericanas, caribenhas, amazônicas (GLISSANT, 2005, pp. 20-21), compreendeu os significados dos sopros e apelos da floresta com seus segredos, suas visualidades, suas invisibilidades. Em síntese, seus saberes formulados nos muitos intercâmbios cultura-natureza, natureza-cultura produziram materialidades/espiritualidades transmitidas por palavras, sons, gestos, olhares, corpos em movimento.

As primeiras comunidades do Daime foram formadas por mulheres e homens da palavra falada, gesticulada; da escola oral que escreve/inscreve no e com o corpo; da "fala cabocla", como preferem alguns. Ouviam as mensagens do mestre e internalizavam seus conhecimentos; "recebiam" os hinos e cantavam para os outros ouvirem; os que ouviam, repetiam, entoavam, cantavam, dançavam e, nesse processo coletivo, os produziam/reproduziam em seus corpos. Desse modo. a palavra era instrumentalizada pelos gestos, olhares, sons. A escrita nunca lhes fez falta e seus saberes/ensinamentos ecoaram com força para além das fronteiras de grupos de negros, afroindígenas e outras misturas que aí se socializavam.

Em palestra proferida na cidade de Rio Branco, no ano de 2009, o jornalista e poeta Antonio Alves, destacou que o "Mestre Irineu recebia seus hinos por revelação divina" e, em seguida, os recitava/cantava para seus familiares e integrantes da comunidade/irmandade, repetindo-os várias vezes, até que estes aprendessem: "o daime é essencialmente musical". A repetição e a memorização, com riqueza de detalhes, estão na base de toda a organização social do daime, estruturando valores e percepções ético-religiosas por intermédio de seus hinários. $^{5}$

\footnotetext{
${ }^{5}$ Antonio Alves, em debate realizado no dia 26/09/2009, na Casa Paroquial da Catedral Nossa Senhora de Nazaré, em Rio Branco, Acre, promovida pelo Instituto Ecumênico, sob a Coordenação do professor e ex-padre Manoel Pacífico da Costa.
} 
Desse modo, o não domínio da escrita por parte dos primeiros mestres e demais integrantes da irmandade, constituiu-se como virtude e força para a organização social do grupo. A cultura do grupo era oral; a forma de produção, trocas e transmissão de seus saberes se ancoravam em diferentes e complexas tradições de oralidade. Afinal, o "ser humano natural não é escritor nem leitor, mas falante e ouvinte", o que implica em um comportar, um pensar, um agir/reagir oralmente (OLSON \& TORRANCE, 1995, 27.).

No entanto, nos dias atuais, parece se evidenciar que, nas comunidades ayahuasqueiras, a força da oralidade tornou-se menos intensa, principalmente, em função da inserção da linguagem escrita em seu interior - a palavra escrita com suas racionalidades e narrativas “congeladas", seus estatutos científicos e ordenamentos sociais racionalistas. Se essa evidência se confirma, um dos desafios centrais colocados aos participantes do curso é o de enfrentar/dialogar com as tensões e, mesmo, com os paradoxos de iniciar um trabalho com a oralidade para "preservar" saberes, conhecimentos e "tradições" em comunidades/irmandades estruturadas em torno de culturas orais.

Nessa direção, no âmbito das casas de memória existentes ou a serem criadas nas comunidades, poderão ser gestadas alternativas e estratégias contra o "esquecimento", mas, os "agentes culturais" e demais organizadores das mesmas, estarão cientes que tal formulação é o reconhecimento da existência de um "vazio" ou de algo que se "rompeu" nos procedimentos de produção e transmissão oral dos saberes/ensinamentos nessas comunidades.

Convencer os "mais velhos a falar" e os "mais novos a ouvir", parece ser outro desafio que se coloca aos "agentes culturais das comunidades ayahuasqueiras". Isso se depreende pela leitura de vários relatos de alunos, em trabalhos de conclusão do curso. Senão vejamos:

O relato de memórias busca guardar conhecimentos, historias de pessoas onde quer
que seja, no bairro, comunidade ou ate mesmo em casa, para que um dia os mais
jovens ouçam e não deixem os costumes e tradições se apagar, de forma a tomar
outros rumos. O que se busca mais nessa ação, é que as grandes riquezas, aquelas
que estão gravadas dentro de cada pessoa não partam ou se percam juntamente com
seu corpo, mas fique gravado ou escrito.
O curso de memória oral me proporcionou certo conhecimento de como entrevistar
uma pessoa e fazer com que essa pessoa relembre o seu passado de forma que venha
recordar suas experiências de vida. Nem sempre as pessoas querem revelar o seu
passado, por isso muitos só falam de momentos bons, onde não se percebe tanta

\footnotetext{
${ }^{6}$ Alzir Ferreira Soares, em Trabalho de Conclusão do Curso "Formação de Agentes Culturais nas Comunidades
} Ayahuasqueiras", Rio Branco, Acre, abril de 2010. 
angústia. Pode-se perceber nas entrevistas realizadas durante o curso que as pessoas se emocionaram, choraram e algumas não queriam nem falar de coisas tristes. ${ }^{7}$

... No dia marcado para a entrevista, enfrentamos dificuldades porque a depoente se recusou a ir ao nosso encontro, no local marcado. Daí foi necessário nos replanejarmos e fomos ao seu encontro, na casa da filha dela. Percebi e senti que sua recusa era porque uma das filhas a estava pressionando com insegurança do destino que seria dado àquela gravação. Ao término da gravação, quando colocamos a fita para rodar, ela deixou transparecer isso, chamando a filha para ouvir a gravação e o resultado foi que a filha se emocionou muito e saiu aos prantos. ${ }^{8}$

Nosso projeto de pesquisa já foi direcionado envolvendo daimistas mais idosos com o objetivo de reunirmos depoimentos a serem preservados em casas de memória em todas as sedes ayahuasqueiras que participaram do curso. Nestes registros constituiremos um acervo de relações de pessoas na sua família e na comunidade e poderemos montar uma cadeia de interpretações que aproximará passado e presente com sua dinâmica viva, suas contradições e suas convergências e oferecerá aos mais jovens mais uma ferramenta de aprendizagem além da repetição, quando esses mais idosos se forem. Um dos nossos entrevistados nos disse que antes era contra a publicização das informações, mas que hoje ele reconhece que é um arquivo vivo da história daimista e afirma/indaga: quem ensinará o certo se nós nos calarmos? ${ }^{9}$

No começo do curso enfrentei alguns obstáculos por parte de pessoas da própria comunidade que não entenderam o objetivo do curso, achando que iria fazer divulgação dos ensinamentos da doutrina e dos conhecimentos dos entrevistados da comunidade. Não foi fácil chegar uma a uma conclusão e dizer para essas pessoas qual o real objetivo, que era trazer para a comunidade as historias de vida de pessoas com muitas experiências e que, com esses depoimentos e ensinamentos, iríamos construir o centro de memória da nossa comunidade. Pois durante as entrevistas com uma pessoa bem idosa que, por sinal, é da comunidade onde estou desde que nasci, eu ouvi dessa pessoa coisas e ensinamentos da doutrina que jamais sabia, e essa pessoa estava ali bem perto de mim eu não estava sabendo valorizar, ou seja, ouvir seu depoimento. Foi preciso a realização desde curso para eu aprender que muitas vezes estamos ao redor de pessoas com uma bagagem belíssima mas, por nunca sentarmos para conversar, deixamos de aprender muito. ${ }^{10}$

Explicar aos depoentes sobre a importância de se registrar a memória oral de determinada cultura, em especial, a do Santo Daime, passa a ser um ato de convencimento para com grande parte dos integrantes da vanguarda daimista. Neste ponto, ao se abordar as pessoas indicadas para registrar seus relatos, todas sentem uma dificuldade em falar de sua vida, apesar da oralidade sempre ter feito parte da vida deles, pois a Doutrina do Daime é repassada, durante décadas, através de histórias de pessoas que conviveram com o Mestre, ou de pessoas que escutaram sobre determinado assunto, ou mesmo através dos hinos. Porém, trazer para um trabalho dessa natureza e oficializar um documento parece bem distante da realidade deles. É bem verdade que registrar a memória oral deles é confidenciar sua história de vida. Ademais, o receio de se desvirtuar o seu depoimento, ou até mesmo tratar assuntos polêmicos, que criaram divergências no passado, traz geralmente um receio de se reviver ou relembrar possíveis desafetos ou lembranças dolorosas. Durante os relatos, as expressões do corpo das pessoas, os atos de esquecimento, grandes pausas, todas nos trazem um entendimento. E o interessante é que se torna um entendimento que chega a ser um discernimento individual para cada ouvinte (...). Chamou-nos atenção, principalmente, a reação das pessoas entrevistadas. Com o

\footnotetext{
${ }^{7}$ Etinaiara De Oliveira, em Trabalho de Conclusão do Curso "Formação de Agentes Culturais nas Comunidades Ayahuasqueiras", Rio Branco, Acre, abril de 2010.

8 Lindalva Brasil da Silva, em Trabalho de Conclusão do Curso "Formação de Agentes Culturais nas Comunidades Ayahuasqueiras", Rio Branco, Acre, abril de 2010.

${ }^{9}$ Marina Brandão Coutinho de Rezende, em Trabalho de Conclusão do Curso "Formação de Agentes Culturais nas Comunidades Ayahuasqueiras", Rio Branco, Acre, abril de 2010.

${ }^{10}$ Ocilene Ferreira da Silva Cruz, em Trabalho de Conclusão do Curso "Formação de Agentes Culturais nas Comunidades Ayahuasqueiras", Rio Branco, Acre, abril de 2010.
} 
receio de relatar sobre suas histórias indagavam, repetidamente, sobre qual objetivo tinham as entrevistas, onde iam ser divulgadas, etc. Após aceitarem registrar os depoimentos, os entrevistados se preocupavam com a colocação das palavras nas frases, ficando, desta forma, um pouco constrangidos, selecionando e filtrando o que iriam dizer, tirando sua naturalidade. Deixando, deste modo, de registrar fatos interessantes que haviam dito nas conversas que antecediam as gravações. ${ }^{11}$

Tivemos uma conversa inicial com a entrevistada, onde foi explicado o objetivo do trabalho que seria realizado. Esse primeiro contato foi feito de uma forma breve, onde a entrevistada não se mostrou muito disposta a dar o seu relato. Por isso, foi necessária uma segunda conversa, mais detalhada, sobre a finalidade do curso. Observamos que a entrevistada continuou mostrando-se insegura, mas conseguimos marcar o local e a data para a entrevista (...) [em outro depoimento] O [entrevistado] começou a contar sua historia de vida, mas quando chegou um determinado momento que ele pediu que fizéssemos perguntas para ele. Essa situação nos causou um pequeno transtorno porque não esperávamos essa reação do entrevistado, ou seja, tivemos que continuar a entrevista fazendo perguntas que foram improvisadas na hora (...) Apesar da boa vontade do entrevistado e de o mesmo ser uma pessoa que gosta muito de conversar, já familiarizado com as pessoas que participaram da entrevista, notamos nervosismo e ansiedade na hora de seu depoimento. ${ }^{12}$

Os trechos de depoimentos, destacados acima, foram retirados das significativas observações e análises feitas pelos alunos e se constituem não como componentes indissociáveis destas reflexões. Parte substancial dos relatórios que integram as análises dos alunos são constituídos por importantes entrevistas com mulheres e homens das diferentes comunidades e linhas do Daime na cidade de Rio Branco.

No ato de escrever este texto, refletindo sobre os significados de nossa participação (na condição de docente), convívio e trocas de experiências com os alunos, durante o curso, procuramos preservar os nomes dos depoentes e não fazer uso indevido de suas falas/entrevistas - às quais tive acesso privilegiado -, posto que não tínhamos e não temos autorização expressa para fazê-lo. As narrativas dos depoentes/entrevistados pertencem, em primeiro lugar, a eles próprios, posto que não são dados ou fontes para pesquisas de quem quer que seja, e sim leituras/interpretações de suas próprias vidas; em segundo lugar, tais depoimentos/entrevistas/histórias de vida pertencem às comunidades onde, coletivamente, produziram e produzem seus saberes, suas trajetórias.

Lendo e ouvindo os impressionantes resultados dos trabalhos de conclusão de curso que foram entregues pelos alunos, mais que corrigir seus "equívocos" ou "erros", fomos surpreendido pela força de suas entrevistas e, mais ainda, de suas reflexões. A motivação e o

\footnotetext{
${ }^{11}$ Clemilda Gomes de Oliveira, Frederico dos Santos França, Herotildes Sales Amim, Rejane Nascimento Teixeira de Souza e Suzy Cristiny da Costa, em Trabalho de Conclusão do Curso "Formação de Agentes Culturais nas Comunidades Ayahuasqueiras", Rio Branco, Acre, abril de 2010.

${ }^{12}$ Haérica Holanda, Israel Silva de Souza e Mírian Dias Lopes, em Trabalho de Conclusão do Curso "Formação de Agentes Culturais nas Comunidades Ayahuasqueiras", Rio Branco, Acre, abril de 2010.
} 
empenho demonstrados nesse curso estão espelhados nos relatórios que devem servir como grande referencial para os desafios que terão que enfrentar, principalmente, porque foram ou estão sendo formados na escola da escrita com seus códigos rígidos, cerceadores. Isso coloca a todos o imperativo de ter que aprender a inserir/incorporar os recursos da oralidade em seus universos mentais.

Para compreender os mais velhos e inserir suas trajetórias nas casas de memórias, os "agentes culturais" das comunidades ayahuasqueiras terão que ampliar e fortalecer a capacidade de ouvir, cujo pontapé inicial foi dado no curso que encerramos: ouvir/ler/traduzir as falas, as percussões, os movimentos dos corpos, as linguagens da oralidade. Essa compreensão da força da oralidade, utilizada no entrecruzamento das culturas afroindígenas e cristãs, utilizada na concepção da doutrina do daime, por Raimundo Irineu Serra, pode ser a chave para enfrentarem os apelos e assédios de todos os aparatos, artefatos e códigos "modernos" que concorrem para esvaziar os significados das tradições orais no presente.

Assim, talvez seja possível superar o paradoxo de inserir a oralidade para "preservar tradições" ou saberes em comunidades/irmandades articuladas pela própria oralidade. Talvez, também, seja possível apreenderem o que os corpos e as experiências dos mais velhos comunicam a todo instante: as casas de memória - em céu aberto - são as próprias comunidades, cujos esteios se assentam naquelas pessoas que não precisam dos "papéis escritos" para entoar/bailar/mirar/regar/alumiar/cultivar as "flores" do "grande jardineiro" e dos demais mestres nas enluaradas noites ou no cotidiano de seus ofícios.

Pensar sobre essa experiência e tentar inseri-la como elemento de reflexão para o cotidiano de nossas práticas docentes, no interior da Universidade Federal do Acre, pode servir de estímulo para nossos diálogos sobre o fazer acadêmico e sobre o significado da formação que temos realizado em cursos de licenciaturas e bacharelados cujos currículos são demasiadamente fechados e não abrem espaço para inserir as trajetórias e os conhecimentos individuais e coletivos dos estudantes que recebemos em sala de aula. Em meio a uma região que convive com milhares de falantes de diferentes línguas indígenas e de complexas práticas culturais ancoradas em tradições de oralidade, os resultados de um curso em que o conhecimento foi sendo tecido como resultado da ação e do encontro/desencontro de alunos, professor e pessoas entrevistadas constituem-se como ponto de partida não apenas para percepções pedagógicas, mas para a renovação política de nossas práticas educacionais. 
Encerramos retornando ao início e ao mestre da oralidade, Hampâté Bâ, para quem o saber é uma luz que existe no homem. Essa luz articula a herança de nossos antepassados que se comunicavam pela fala, gesto, olhar; pelos sons dos ventos, movimento das águas, posição dos astros; pelas percussões; pelos sonhos, pré-visões, premonições; pelas coisas visíveis e invisíveis. Em uma palavra, pela oralidade. O relato oral é um todo complexo, uma totalidade que comunica sem cansar, sem se exaurir. Frente ao relato oral, ensina-nos o velho mestre africano, temos que estar atentos ao todo e a tudo; é preciso registrar não somente o conteúdo da fala, mas, "toda a cena - a atitude do narrador, sua roupa, seus gestos, sua mímica e os ruídos do ambiente, como os sons da guitarra que o griot Diêli Maadi tocava enquanto Wangrin me contava sua vida, e que ainda escuto..." (HAMPÂTÉ BÂ, 2003, pp. 13-14).

\section{REFERÊNCIAS}

BENJAMIN, W. Magia e técnica, arte e política (Obras escolhidas, vol. I). Tradução de Sérgio Paulo Rouanet. $5^{a}$ ed., São Paulo: Editora Brasiliense, 1993.

Bosi, E. O tempo vivo da memória: ensaios de psicologia social. $2^{\text {a }}$ ed., São Paulo: Ateliê Editorial, 2003.

GLISSANT, E. Introdução a uma Poética da Diversidade. Tradução de Enilce Albergaria Rocha. Juiz de Fora: Editora da UFJF, 2005.

HAMPÂTÉ BÂ, A. Amkoullel, o menino fula. Tradução de Xina Smith de Vasconcellos. São Paulo: Pala Athena/Casa das Áfricas, 2003.

OLSON, D. R. \& TORRANCE, N. Cultura escrita e oralidade. Tradução de Valter Lellis Siqueira. São Paulo: Editora Ática, 1995.

PORTELLI, A. "A filosofia e os fatos: narração, interpretação e significado nas memórias e nas fontes orais". In: Tempo - Revista Digital de História do Departamento e do Programa de Pós-Graduação em História da Universidade Federal Fluminense. Rio de Janeiro: UFF, vol.1, n.2, 1996, pp. 59-72.

SARLO, B. Tempo Passado: cultura da memória e guinada subjetiva. Tradução de Rosa Freire D’Aguiar. São Paulo: Cia das Letras; Belo Horizonte: Editora da UFMG, 2007. 